\section{Embryo research (contd)}

SIR - The status of the early human embryo has been background music for much dancing on the head of a pin. The latest example is provided by C.B. Goodhart (Nature 14 March, p.126). He finds justification for "use of IVF embryos for experimental work expected to result in death" in the following argument. The fertilized egg ex utero is like an unfertilized egg in that voth require external action to realize their potential to become an adult, the fertilized egg requiring activation by a sperm (or a substitute). But, the argument continues, fertilization does not really change "right to life" status because that right relates to being human and alive which is characteristic of both gametes and zygotes. Ergo, since zygotes and early embryos in vitro will, like unfertilized eggs in vitro, die without external help, both are ethically available for experimentation unto death.

After vertigo subsides, one asks why the discovery does not apply to zygotes or early embryos in normal reproduction. Easy "the embryo in utero has of itself (sic) the full potential to complete its development without any further intervention from outside". Possible parallel - the bank robber, once inside the bank and having cowed the cashier, has earned his ill-gotten gain because he can (barring police interference) carry it outside without further external aid.

But now, in truth, the embryos (blastocysts) in utero and ex utero have exactly the same potential, as demonstrated by normal development of ex utero blastocysts when transferred to a physiologically prepared uterus. Moreover, the state of both is very different from that of an unfertilized egg by virtue of the genetic individuality conferred by gamete fusion.

If there are good reasons why IVF embryos should be available for clinical investigation (and I believe there are), the justification is better provided through contemporary ethics and science, rather than from a return to scholasticism.

ClifFord GrobSTEIN

Program in Science, Technology and Public Affairs,

University of California, San Diego,

La Jolla, California 92093, USA

SIR - C.B. Goodhart's argument (Nature 14 March, p. 126) that embryos fertilized ex utero lack independent viability and therefore are not potential human beings like their brothers and sisters in the womb after natural conception, is at first glance attractive, in that it might allow one for instance to be anti-abortion yet pro-experimentation on very early embryos; but it involves the debatable assumption that what comes naturally is outside our control in the sense that we can interfere with it only negatively, whereas for an embryo ferti- lized in vitro, positive intervention is required for its survival. Is this a legally or morally valid distinction, especially for physicians and surgeons dedicated to interference with nature and rightly regarded as culpable if they do not do so when asked in the supposed interests of a patient, and might not feminists enquire whether their sex must regard themselves as the passive and vegetative receptacles of an embryo implanted in their womb by any male (or even by the Holy Ghost) who succeeds in depositing in them the necessary seed? Surely it is time we left the suspect word "natural" to advertisers of semisynthetic foodstuffs and took it upon ourselves to live up to the very worrying responsibility that we have for ordering our own destinies; or do we no longer assume that what man does is no longer part of nature since he is no longer mainly concerned with adaptation to his environment, but can adapt it to himself?

JOHNA. DAVIS

Department of Paediatrics,

University of Cambridge Clinical School,

Level 8, Addenbrooke's Hospital,

Hills Road, Cambridge CB2 2QQ, UK

\section{Value-laden science}

SIR - M. Hammerton's letter (Nature 31 January, p.343) demonstrates unwittingly that it is more difficult to identify valuefree science than the unwary might realize.

The statement which Hammerton believes to be value free, "The lethal dose of cyanide is $x \mathrm{gm} /$ kilo body weight", contains implicit value judgements in the definition of "lethal dose" and how this relates to the real world, for example a coroner's inquiry. Is the lethal dose for a particular human individual determined better on the basis of extrapolation of $\mathrm{LD}_{50}$ s from animal experiments, or from a smaller sample of mortality data collected from other humans? Furthermore, independent of the definition of "lethal dose", if the forensic evidence indicates that the victim has a body burden of $0.2 x$ $\mathrm{gm} / \mathrm{kilo}$, was cyanide the cause of death? Whatever the body burden of cyanide, what other factors ignored by the forensic evidence (such as the psychological state of the victim) could be relevant to the death? To answer such questions, value judgements are unavoidable.

Ironically, the statement which Hammerton believes is value-laden, "I am going to poison my spouse", can be interpreted as a statement of pure intention or as a prediction of one's own future behaviour. With these interpretations, although the statement is unpleasant, it contains no ethical, social, political or other evaluative judgements, and so can be considered to be value free. To make it clearly value-laden, one could re-interpret it as "Rather than (say) shoot my spouse, I shall use poison", or one could modify it to "It is good/socially desirable/profitable to poison my spouse".

Although the matter is controversial amongst philosophers of science, people might wish to hold a "pure" mathematical statement, such as $2+2=4$, is value free in its content. However, even then the context could in some cases make it value laden: for instance, if it represented a reductionist approach to a scientific problem which some researchers believe can only be treated adequately by a holistic approach.

MARK DIESENDORF

CSIRO,

Division of Mathematics \& Statistics, Canberra ACT 2601,

Australia

\section{Sizewell inquiry}

SIR - Your leading article (28 February, p.723) on the prospects for UK energy policy following the ending of the Sizewell inquiry and the coal industry strike raises a number of important questions. Unfortunately, it would demand too much space adequately to respond to all of them. I wish therefore simply to point out one factual error rather than to take issue on matters of interpretation.

You state that part of the explanation for the extreme length of the Sizewell inquiry (340 sitting days taking just over 2 years) was the inspector's decision at the outset to allow documentary evidence to be accepted only if it was read aloud, but this is not true. The inspector did require the proponent party, that is, Central Electricity Generating Board witnesses, to read their proofs of evidence in full so that their case would be fully set out in public. This is not so with the opposition. Groups or individuals who appeared in person were requested to summarize their evidence, sometimes to the considerable disadvantage of the objectors, as additional personal time had to be devoted to preparing such a summary in a cogent but no less coherent form.

In addition there were 112 entirely written submissions, of which the inspectors stated on the final inquiry day (p.79 in transcript): "I would like to add that I will take into account all these written representation in preparing my report."

I fear that because of your editorial stance that the structure and scope of the proceedings were inappropriate to the issues that ought in your judgement to have been under review, you may have overlooked some very important aspects of changes in energy policy that undoubtedly have emerged from the inquiry itself, such as nuclear waste management. No doubt these issues will persist in new, rather less exotic forums.

DAVID LOWRY

Energy Research Group,

Open University,

Walton Hall,

Milton Keynes MK7 6AA, UK 